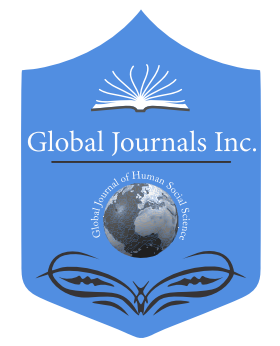

GLOBAL JOURNAL OF HUMAN-SOCIAL SCIENCE: C

SOCIOLOGY \& CULTURE

Volume 20 Issue 8 Version 1.0 Year 2020

Type: Double Blind Peer Reviewed International Research Journal

Publisher: Global Journals

Online ISSN: 2249-460X \& Print ISSN: 0975-587X

\title{
Human Value of the Elderly in the Disposal Society
}

By Keite Crisóstomo Bezerra \& Carolina Yukari Veludo Watanabe

Federal University of Rondônia

Abstract- This article discusses how the social transformations related to the expansion and changes of the capitalist system affect the dignity and human value of the elderly, from the economic, productive, functional, and social aspects. The theoretical approach was used to design this work, which resulted in the close relationship between the capitalist model's growth to its parasitic form and the phenomenon of social discard of the elderly population.

Keywords: elderly; disposal society; human value.

GJHSS-C Classification: FOR Code: 160899

Strictly as per the compliance and regulations of:

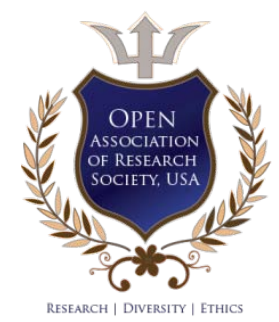

(c) 2020. Keite Crisóstomo Bezerra \& Carolina Yukari Veludo Watanabe. This is a research/review paper, distributed under the terms of the Creative Commons Attribution-Noncommercial 3.0 Unported License http://creativecommons.org/licenses/by-nc/ 3.0/), permitting all non-commercial use, distribution, and reproduction in any medium, provided the original work is properly cited. 


\title{
Human Value of the Elderly in the Disposal Society
}

\author{
Keite Crisóstomo Bezerra ${ }^{\alpha}$ \& Carolina Yukari Veludo Watanabe ${ }^{\sigma}$
}

Abstract-This article discusses how the social transformations related to the expansion and changes of the capitalist system affect the dignity and human value of the elderly, from the economic, productive, functional, and social aspects. The theoretical approach was used to design this work, which resulted in the close relationship between the capitalist model's growth to its parasitic form and the phenomenon of social discard of the elderly population.

Keywords: elderly; disposal society; human value.

\section{INTRODUÇÃO}

$\int$ a Antiguidade clássica à Idade Média, a sabedoria associava-se à velhice. A velhice era como um troféu carregado apenas por quem atingisse tal fase da vida; entretanto, a partir da modernidade, os laços que uniam conhecimento, sabedoria e a consequente valorização da velhice foram se perdendo com o tempo, à medida que $\mathrm{O}$ capitalismo avançou (PAULA, 2016).

Neste passo, embora as sociedades préindustriais e sociedades não ocidentais tivessem uma forma de marcação etária como critério de diferença, foi com a modernidade que se deu relevância à institucionalização do curso da vida, período em que foram universalizadas e regulamentadas as sequências etárias, fazendo com que os projetos e anseios individuais e coletivos fossem também definidos por esta institucionalização e pelo sistema capitalista(SILVA; SILVA, 2018).

Assim, a medida em que o modelo capitalista se expandia, a velhice se tornava umproblema crescente, surgindo daí uma maior preocupação com os idosos. Então, em meados dos anos 1970, o velho passou a ser tratado como um problema social, mas não em razão da materialidade do ser humano e da mudançasbiológicas naturais à todos indivíduos, e nem muito menos em razão do crescimento demográfico dessa parcela da população (TEIXEIRA, 2018).

A experiência pessoa envelhecida passou a ser vista como um problema social a partir da noção da perda de valor de usopara o capital,vindo a ocupar de forma pejorativa o local daqueles que não são mais

Author $\alpha$ : Master's student in the Graduate Program in Human Rights and Justice Development. BSc. in Law. Federal University of Rondônia, Brazil. e-mail: crisostomokeite@gmail.com e.com

Author o: Post-doctorate in Business Administration, Ph.D, M.Sc in Computer Science. Professor at the Federal University of Rondônia, Brazil, in the Master's program in Human Rights and Justice Development and Master's program in Administration.

e-mail: carolina@unir.br capazes de gerar riquezas nem de participar do processo produtivo e de consumo, razão pela qual passaram a ser tidos como humanos descartáveis para esse sistema (RAMOS, 2014).

Deste modo, o antigo laço que unia a velhice à sabedoria,ao acúmulo de experiência, ao aprendizado de vida e ao seu local de guardiões do conhecimento na sociedade, foi se desfazendo a tal ponto de se esvaziar quase que por completo a sua autonomia, fato que tem reflexo significativamente no valor humano do ser envelhecido.

Neste contexto, o problema que motivou esse artigo pode ser descrito de forma interrogativa das seguintes maneiras: na moderna sociedade do consumo, da liquidez e do descarte como o valor humano dos velhossão afetados? Qual o lugar da população idosanessa sociedade?

Esse estudo se justifica já que há o paradoxo existente entre o aumento significativo da população idosa em todo mundo, inclusive de maneira exponencial no Brasil, e a constante desvalorização como seres humanos ante as exigências do sistema capitalista moderno.

De maneira a reforçar tal paradoxo, segundo o Fundo Populacional da Organização das Nações Unidas (UNFPA, 2012), em 2012, oitocentos e dez milhões de pessoas tinham 60 anos ou mais, constituindo $11,5 \%$ da população global, tendo comoprojeção desse número o aumento de 1 bilhão em menos de dez anos e mais que o dobro até 2050, alcançando-se assim a marca de 2 bilhões de pessoas com mais de 60 anos, ou seja, 22\% da população global.

Corroborando com essa estimativa de 2012, o Plano de Ação Sobre a Saúde das Pessoas Idosas, incluindo envelhecimento ativo produzido pela Organização Pan-Americana da Saúde,publicadoem julho de 2019, revela que na "próxima década, a população com mais de 60 anos na América Latina e caribenha representará pelo menos $18 \%$ da população em geral, número que atingirá quase 25\% até 2050 e até 30\% em vários países"(UNFPA, 2012, p.1).

E ainda, segundo o Plano de Ação sobre a Saúde das Pessoas Idosas, incluindo envelhecimento ativo e saudável para o período 2009-2018 da Organização Pan-Americana da Saúde (2019) se estima queo número de pessoas com 60 anos ou mais que irão necessitar de cuidados prolongados mais que 
triplicará nas Américas nas próximas três décadas, passando dos 8 milhões para um número aproximado de 27 a 30 milhões até 2050.

Em razão disto, o objetivo geral deste artigo édiscutirquestões relacionadasao valor humano, à dignidade da pessoa humana e às mudanças trazidas no processo de consolidação do capitalismo e à consequente expansão das desigualdades sociais, com vistas à pobreza e à exclusão social do idoso na dita sociedade do descarte, principalmente com relaçãoaos valores sociais e morais retirados dessa parcela da população pelo referido sistema.

Para atingir o objetivo geral, foram elencados os seguintes objetivos específicos: discorrer acerca da dignidade da pessoa humana e valor humano, traçar as transformações que acarretaramno estabelecimento dasociedade moderna do maciço descarte humano e,por último, a análiseda pessoa idosa no contexto da sociedade do descarte humano e a problemática dos descartáveis idosos.

A abordagem utilizada é a qualitativa. Foram utilizadas a técnica da revisão bibliográfica a partir de pesquisas, estudos, livros e artigos jurídicos, sociológicos, médicos e históricos acerca dos elementos relacionados à problemática analisada com foco na pessoa idosa e sua relação com a sociedade do capital.

Como forma de embasamento para a reflexão conclusiva, este estudo foi dividido em quatro seções, em que cada uma corresponde a um objetivo específico relacionado ao problema central em análise.

$\mathrm{Na}$ segunda seção, são apresentadas reflexões sociológicas sobre os aspectos mais intrínsecos dos seres humanos que são a natureza, condição e dignidade da pessoa humana, e como estes são afetados quando o ser humano em idade avançada é excluído e tolhido de sua natureza social.

$\mathrm{Na}$ terceira seção, buscam-se estabelecer algumas das principais transformações sociais que colaboraram para a expansão do modelo capitalista e sua consolidação na forma moderna, chamada por Bauman (2010) de parasitária, bem como realizar uma breve digressão sobre fenômenos sociais da desigualdade, pobreza e exclusão social, com vistas a diferenciá-los e estabelecer ligações entre elas, de modo a situar em que ponto essas formas de marginalização de seres humanos tocam o envelhecimento.

Na quarta seção, é apresentada uma crítica às causas pelas quais o envelhecimento se tornou um problema social e fator de violações sistêmicas à dignidade da pessoa humana, bem como de quão o descarte humano é prejudicial e violento para a sociedade como um todo, buscando dessa forma deixar pontuado como o processo de consumo e produção de uma sociedade capitalista parasitária leva à criação da pilha de lixo humano, com diversas pessoas sendo tidas como descartáveis.

Por fim, na quinta seção, são feitas reflexões conclusivas acerca da problemática estabelecida nas quatro seções anteriores.

\section{O Valor Humano Do Idoso}

"Na memória do pensamento europeu, a velhice tem sido um recurso útil para se refletir sobre a condição humana", sendo o reconhecimento da diversidade do envelhecimento o primeiro passo para abordar o tema relativo aos valores humanos e sociais da velhice (LARANJEIRA, 2010, p.764).

O processo do envelhecimento provoca no organismo de cada ser humano diversas modificações biológicas, psicológicas e sociais, entretanto, é a partir da chamada velhice que este processo aparece de forma mais evidente e individualizado (SANTOS, 2010).

Deste modo, é certo que o envelhecer é único para cada pessoadevido às várias capacidades que compõem a pessoa humana e diametralmente afetam a chamada condição humana, de modo que o reconhecimento dessa individualidade na forma de envelhecer em cada pessoa perpassa pela compreensão destes conceitos e do que seja natureza humana.

Para Hannah Arendt (2008, p. 17-18), que tem a condição humana como algo mais que as condições nas quais a vida foi dada ao homem (natureza humana), "a condição humana não é o mesmo que a natureza humana, e a soma total das atividades e capacidades humanas que correspondem à condição humana não constitui algo que se assemelhe à natureza".

Logo, apesar de o envelhecimento ser o mais natural dos processos da vida e estar intimamente ligado à natureza humana, o envelhecer implica mudanças particulares nas capacidades dos indivíduos, as quaisjuntamente com os processos sociais podem afetar diretamente a condição humana e repercutir, a depender das circunstâncias, na dignidade da pessoa humana (conceitos próximos, mas distintos).

$\mathrm{Na}$ teoria Kantiana, a dignidade é o que distingue as pessoas dos animais e das coisas, se constituindo fins em si mesmas, para ele a "dignidade é um valor incondicionado, incomparável, para o qual só o termo respeito fornece a expressão conveniente da estima que todo ser racional the deve tributar. A autonomia é, pois, o princípio da dignidade da natureza humana, bem como de toda natureza racional"(KANT, 2011, p. 33).

Nesse sentido, conforme ensina Sarmento (2016, p. 35), "a autonomia, para Kant, é uma característica universal dos seres racionais capazes de descobrir e de se autodeterminar pela lei moral". 
Assim, denota-se que da simples existência humana se desenvolve uma grande constelação axiológica de valores inerentes à pessoa humana, os quais estão intimamente ligados não só às singularidades de cada um, mas também à integração com a coletividade.

Esses valoresafetam diretamente quatro pontos especiais da vida humana, os quais, segundo Fernandes (1997), são o tratamento equitativo, a garantia de igualdade, o direito à autonomia, estimulando a participação social e familiar, e,por fim, e não menos importante, a preservação da dignidade humana, respeitando sua imagem, assegurando-lhe consideração nos múltiplos aspectos que garantam satisfação de viver a velhice.

Para Boff (2005), haveria mais um ponto especial da vida humana, que é a expressão social do homem, já que, segundo sua teoria, o ser humano apresenta-se como um nó de relações, o qual foi feito para voar em todas as direções, inclusive para dentro de sua interioridade, não existindo o ser humano sem as relações, razão pela qual a estrutura pessoal do ser humano reside no dar, receber e retribuir.

\section{Assim, para o referido autor:}

Nada mais violento que impedir o ser humano de se relacionar com a natureza, com seus semelhantes, com os mais próximos e queridos, consigo mesmo e com Deus. Significa reduzi-lo a um objeto inanimado e morto. Pela participação, ele se torna responsável pelo outro e cocria continuamente o mundo, como um jogo de relações, como permanente dialogação (BOFF, 2005, p.151).

Dada a importância da expressão social e da dignidade da pessoa humana idosa é que o artigo 10 do Estatuto do Idoso prevê que: "É obrigação do Estado e da sociedade, assegurar à pessoa idosa a liberdade, o respeito e a dignidade, como pessoa humana e sujeito de direitos civis, políticos, individuais e sociais, garantidos na Constituição e nas leis" (HEBLING; RODRIGUES, 2006).

Contudo, é exatamente nesse ponto que o sistema social e econômico adotado pela maioria das nações afeta o valor humano da pessoa idosa, tendo em vista que o natural processo de envelhecimento apresenta grandes modificações sociais na vida da pessoa envelhecida, sendo as principais: as alteraçõesrelativas àfunção social, diminuição de produtividade, poder físico e econômico e, principalmente, do quanto se consome (SANTOS, 2010), as quais, a depender de como a sociedade está organizada,comprometem de forma mais ou menos intensa a sensação de autonomia e a capacidade de autodeterminação.

Nesse entorno axiológico humano e social é que as mudanças estruturais ocorridas na sociedade se desenvolveram de tal maneira a serem capazes de relativizar o valor de cada pessoa humana, tendo em vista que adignidade da pessoa humana se deslocou da simples existência para a valoração conforme a posição funcional nas sociedades de massas humanas privadas. E é exatamente"nessas massas que se encontra o idoso como excluído" (FORNASIER; LEITE, 2018, p.9).

Nota-se, assim, que a dignidade e o valor das pessoas, em especial das pessoas idosas, foi gradualmente se alterando, conforme foram se transformando também as concepções de tempo, trabalho e consciência de classe (SILVA; SILVA, 2018).

Com isso, percebe-se que a população idosa perdeu gradativamente o reconhecimento de outrora depessoa portadora de conhecimentos e sabedoria, e, portanto, digna do seu valor humano, como contribuinte por meio de seus ensinamentos e de seu tempo de vida economicamente produtivo (CEDENHO, 2014).

\section{ili. Sociedade Do Descarte Humano}

A gênese do sistema capitalista se deu com a apropriação das formas econômicas já existentes, para somente depois engendrar suas formas próprias, de maneira progressiva (MAZZEO, 1995).

Entretanto, de acordo com Teixeira (2018), a partir da década de 1970 ocorreu a expansão do capital financeiro para setores nãomercantilizados, sendo este um dos marcos das transformações mais sensíveis do sistema produtivo e, consequentemente, das superestruturas ideopolítica de toda sociedade.

As naturais modificações sociais associadas aos processos de restruturação produtiva, de financeirização e de globalização, juntamente com a superestrutura político-ideológica e jurídica do Estado, rearticularam os moldes liberais, garantindo a plena expansão do capitalismo(TEIXEIRA, 2018).

Depois dos anos 1970, além da promoção de uma verdadeira metamorfose no mundo do trabalho, no Estado do Bem-Estar e no espaço urbano, se contrafez uma nova representação para a existência humana (VÉRAS; FELIX, 2016).

$\mathrm{Na}$ teoria arendtiana, essaEra se iniciou com a glorificação da teórica do trabalho, e resultou na transformação efetiva de toda a sociedade em uma sociedade operária (ARENDT, 2008).

Conforme argumenta Teixeira (2018), nesse cenário, qualquer pessoa que estivesse fora dessa sociedadeoperária, estaria fora da vida, excluído das condições de reprodução social; no caso do envelhecimento, do mundo público, das relações sociais, condição esta que implica na desvalorização social e humana por não contribuir para a riqueza social e para a reprodução biológica posta.

Contudo, a sociedade moderna transferiu o peso social da produção para o mercado de consumo, "as fontes de lucro do capitalismo se deslocaram ou foram deslocadas da exploração da mão de obra 
operária para a exploração dos consumidores" (BAUMAN, 2010). Deste modo, o desenvolvimento do capitalismo criou processos de destruição tanto dentro como fora do âmbito do trabalho assalariado, emplacando uma dinâmica social com forte tendência de exclusão ou desconexão do sistema social de produção (SOUZA; GRILLO, 2009).

Assim, conforme Bauman (2007), a sociedade operária continuou sua mutação e evoluiu para o que ele chama de "sociedade líquida", a qual vem projetando o mundo e todos os seus fragmentos animados e inanimados como objetos de consumo, que perdem sua utilidade e, portanto, o seu poder e valor, enquanto são usados.

De forma imperativa, Baumanafirma em seu livro "Vida para o Consumo" que:

Os membros da sociedade de consumidores são eles próprios mercadorias de consumo, e é a qualidade de ser uma mercadoria de consumo que os torna membros autênticos dessa sociedade. Tornar-se e continuar sendo uma mercadoria vendável é o mais poderoso motivo de preocupação do consumidor, mesmo em que geral latente e quase nunca consciente (BAUMAN, 2008, p. 76).

Deste modo, conforme Solange Teixeira (2006, p. 40), nessa sociedade "o ser humano só interessa enquanto força de trabalho, fonte de mais-valia e de valor, ou enquanto consumidor". O que confirma a liquidez e afirmação de Bauman (2010), que sem meias palavras, assevera que o capitalismo é um sistema parasitário, posto que nesse sistema a capacidade de durar, das coisas ou das pessoas, exige apenas que sirvam durante algum tempo para que depois sejam destruídos ou descartados de alguma forma quando se tornarem obsoletos, o que acontecerá forçosamente.

É bem por isso, que "a vida não se tornou melhor no capitalismo, mas pior, porque do conflito central do capital derivam necessariamente certos problemas que o próprio modo de produção não pode conter: a desigualdade social, em primeiro lugar, mas em seguida tudo o que dela decorre ou que ela envolve", como a exclusão social, pobreza, dominação, fome (PAULA, 2016, p. 272).

Logo, a análise e a relação dessas questões sociais decorrentes do sistema capitalista são importantes para que se entenda o real impacto desse sistema no modo de vida daqueles que não mais se mostram "úteis". Contudo, devido à complexidade de cada uma, é necessário saber reunir sem confundir e distinguir sem separar (SIQUEIRA-BATISTA; SCHRAMM, 2005).

Pois bem, quanto àconcepção de pobreza, Sen (1999) faz sua análise do fenômeno e chega à conclusão de que elanão deve se limitar ao aspecto financeiro, pois existe um argumento bom para não terminar a análise apenas com a apreciação da renda, o de que a vida humana não se limita somente a esfera financeira.

A partir dessa concepção, o estudo do fenômeno da pobreza ampliou seu enfoque para a chamada privação relativa, que introduziu variáveis mais amplas ao conceito de pobreza existente, chamando atenção para o fato de que as pessoas sofrem privações em diversas esferas da vida, e que ser pobre não implicaria somente em privação material, mas sim da privação das capacidades básicas do indivíduo (CRESPO; GUROVITZ, 2002).

Tratando-se especificamente da população idosa, fatos como o acelerado crescimento demográfico, o cenário econômico de informalidade e o enfraquecimento do apoio familiar podem estar relacionados com o quadro de pobreza e hipervunerabilidade dessa parcela da população que vive em países em desenvolvimento (ASRI, 2019).

Quanto à desigualdade, Tedesco explica que "enquanto as desigualdades tradicionais eram fundamentalmente intercategoriais, as novas desigualdades são intracategoriais" (2002, p. 19). Posto que, foi se perdendo a homogeneidade dentro de cada categoria, produzindo-se assim no interior delas as novas desigualdades econômicas e identitárias (FERNANDES, 2000).

Assim, a nova desigualdade separa materialmente, mas unifica ideologicamente. Isso porque se caracteriza basicamente por criar uma sociedade dupla, em que se exclui reciprocamente. Mesmo todos aqueles, que embora parecidos na forma, nas ideias individualistas e nas competições, outrora são completamente desiguais em oportunidades (MARTINS, 2009). Dessa forma, "estas novas desigualdades dão origem a um especial sentimento deexclusão social" (FERNANDES, 2000).

É bem por isso que o aumento significativo da desigualdade social é um dos fenômenos mais relevantesdas transformações sociais atuais, sendo um dos fatores associados a este fenômeno as modificações ocorridas na organização do trabalho, que têm provocado o movimento de exclusão da participação no ciclo produtivo (TEDESCO, 2002).

Entretanto, apensar intimamente ligada à desigualdade social e à participação no ciclo produtivo, a exclusão social se apresenta como um processo multidimensional dinâmico, de natureza interativa (MACLEOD et al., 2017), que engloba e afeta muitos fatores tais como como:

... falta ou negação de recursos, direitos, bens e serviços e incapacidade de participar dos relacionamentos e atividades normais, disponíveis para a maioria das pessoas em uma sociedade, seja em áreas econômicas, sociais, culturais ou políticas. Afeta tanto a qualidade de vida dos indivíduos e a equidade e coesão da sociedade como um todo (LEVITAS et al., 2007, p. 25). 
Para Gaudêncio Frigotto (2010), a noção de exclusão social se constituiu como um sintoma da materialidade que assumiu a forma capital e seu poder destrutivo no capitalismo tardio. Segundo ele nas sociedades tradicionais era realizado sob a lógica familiar, uma vez que as famílias eram distribuídas em estratos.

Contudo, com o advento da modernidade, as pessoas passaram a ser excluídas de modo muito mais paradoxal, e para além do estrato familiar (FORNASIER; LEITE, 2018).

A exclusão moderna passou a atingir diversos setores sensíveis da vida humana, ocorrendo de modo que ao não preencher ou satisfazer os requisitos e padrões estabelecidos de inclusão, o indivíduo tem o acesso a tais setores negado, havendo a partir daí um tipo de exclusão em cadeia, em que uma exclusão serve de fundamento para as demais formas de exclusão.

Para Pierre Bourdieu e Loïc Wacquan (2000), o termo exclusão passou a ser utilizado em todos os países avançados, com altos padrões, pela mídia e jornalistas de primeiro escalão sem origem aparente, sendo para eles:

[...] o produto de um imperialismo apropriadamente simbólico: onde seus efeitos são tão mais poderosos e perniciosos porque ele é veiculado não apenas pelos partidários da revolução neoliberal que, sob a capa da "modernização", entende reconstruir o mundo fazendo tábula rasa das conquistas sociais e econômicas resultantes de cem anos de lutas sociais, descritas, a partir dos novos tempos, como arcaísmos e obstáculos à nova ordem nascente, porém também por produtores culturais (pesquisadores, escritores, artistas) e militantes de esquerda que, em sua maioria, ainda se consideram progressistas. (BOURDIEU; WACQUANT, 2000 p.1)

Assim, a exclusão moderna tende a substituir a relação de exploração. Se comparados os modelos, tornam-se evidentes as distinções dos vínculos entre exploradores e explorados e incluídos e excluídos (TEDESCO, 2002), já que na exploração há uma relação necessária para que se mantenha o sistema, e, na exclusão,por outro lado, há uma cisão entre os atores sociais.

Assim, Frigotto (2010, p. 422) chega à conclusão de que "a exclusão social é uma categoria que vai sendo assumida nos embates políticos tanto para explicitar questões de gênero e etnia, como, e especialmente, para designar problemas da perda de direitos".

Dessa forma, seja num cenário global ou local, é facilmente identificado um grande e heterogêneo grupo de indivíduos que por diversas circunstâncias sofrem com os inúmeros e modernos tipos de exclusão em diversos campos da vida, a exemplo das pessoas com deficiência, das mulheres, dos desempregados, imigrantes, perseguidos políticos, idosos e tantos outros.

Nesse panorama, Niklas Luhmann, já em 1997, revelava que para ele o pior cenário imaginável do próximo século dizia respeito a uma sociedade que terá que aceitar o metacódigo de inclusão/exclusão. Isso significaria a aceitação de que alguns seres humanos são pessoas e outros apenas indivíduos; alguns são incluídos em sistemas de função para carreiras e outros excluídos desses sistemas, permanecendo corpos que tentam sobreviver no dia seguinte; alguns são emancipados como pessoas e outros são emancipados como corpos (LUHMANN, 1997).

A pobreza, desigualdade e a exclusão social são fenômenos sociais que apresentam íntima ligação entre si e dizem respeito não somente a problemas econômicos, mas também às condições de existência, capacidades, qualidade de vida. Além disso, esses três fenômenos são indicadores do quão adoecida está a sociedade como um todo (SIQUEIRA-BATISTA; SCHRAMM, 2005).

Tal cenário de "exclusão social sob a forma de sobrantes e descartáveis é tomada como sintoma de ampliação e radicalização da desigualdade de classe e entre as classes sociais, e sinaliza uma realidade mais radical da crise da forma capital" (FRIGOTTO, 2010, p. 427).

\section{O Idoso e A Sociedade Do Descarte}

No contexto da sociedade capitalista parasitária, há a identificação de uma série de excluídos. Essa exclusão pode ocorrer por questões sociais, como a incapacidade de produzir ou consumir, nacionalidade, comportamento considerado incorreto e outros por características biológicas que são consideradas socialmente pejorativas, como sexo, genética, incapacidades físicas, psíquicas e idade. Entre estes últimos encontram-se os idosos, sobre os quais muito já se comunicou - e se comunica - em diversos sistemas sociais, ao longo da história (FORNASIER; LEITE, 2018).

Quando visto pelo enfoque social, o envelhecer assume diversas posições e valores que são definidos e criados principalmente pelas construções sociais e pelos modos de produção adotados por cada sociedade.

Na civilização oriental, especialmente na China, desde a antiguidade até os dias atuais, o idoso recebeu um valor diferenciado e uma posição privilegiada. Por outro lado, na filosofia ocidental, existia uma tensão entre o idoso-excluído e o idosoventuroso, a qual perdura também até hoje (FORNASIER; LEITE, 2018). Entretanto, ambas sofreram mudanças de perspectiva. 
Nas sociedades pré-industriais e sociedadesnão ocidentais já existia a marcação etária como critério de diferença. Contudo, foi na modernidade que se deu relevância à institucionalização do curso da vida, universalizando e regulamentando as sequências etárias, fazendo com que projetos e anseios individuais e coletivos fossem também definidos por esta institucionalização e pelo sistema capitalista (SILVA; SILVA, 2018).

Conforme indicam Braga, Leite e Bahia:

(...) a partir do século XIX, na medida em que o processo de industrialização avançou, ocorreu também a exigência de mão de obra mais qualificada, a qual requeria tempo e gastos para sua preparação. Dentro desse contexto, passou-se a ser conveniente que os trabalhadores também vivessem (produtivamente) mais para recompensar os recursos gastos com a sua capacitação (BRAGA; LEITE; BAHIA, 2017, p. 432).

Dessa forma, na era industrial reforçou-se a exclusão de outrora. Eis que o velho não corresponderia a esse sistema, devido às suas capacidades e às necessidades velozes e bem calculadas da economia, razão pela qual, o avançar da idade e da expectativa de vida, proporcionadas pelo desenvolvimento científico e econômico industrial, passou a demandar um envelhecimento com maior produtividade (FORNASIER; LEITE, 2018).

Assim, os conceitos de velhice e envelhecimento foram cada vez mais atrelados aos modos de produção das sociedades, os quaispassaram a influenciar decisivamente a forma como homens e mulheres iriamenvelhecer (SILVA; SILVA, 2018).

Entretanto, essa fase da vida não era, até a consolidação do modelo capitalista, objeto de saberes. Sobre a velhice não incidia nenhum valor, nenhum discurso, nenhuma preocupação (RAMOS, 2014).

Essa sociedade capitalista que de início passou a se preocupar de forma mercantilizada com a extensão do curso da vida, sofreu diversas mutações e existe de forma hegemônica hoje com interesses e prioridades distintas daquela.

Logo, conforme leciona Solange Maria Teixeira, o envelhecimento como "problema social" não foi o resultado mecânico do crescimento do número de pessoas idosas, como tende a sugerir a noção ambígua de "envelhecimento demográfico" (TEIXEIRA, 2006, p. 29).

A problemática social da velhice foi formulada desconsiderando os fundamentos materiais da existência humana, camuflando o fato de que foi a classe trabalhadora, formada pelos homens mercadoria, que aciona o processo produtivo, a protagonista da tragédia do fim da vida (HADDAD, 2017).

Contudo, as sociedades, desde a consolidação do modelo capitalista, passaram por diversas reformas,
- que acarretou a mudança dos paradigmas e o avanço dos novos modelos de capitalismo, chegando, segundo Bauman $(2010$, ) em sua forma parasitária, que segundo ele:

Como todos os parasitas, pode prosperar durante certo período, desde que encontre um organismo ainda não explorado que Ihe forneça alimento. Mas não pode fazer isso sem prejudicar o hospedeiro, destruindo assim, cedo ou tarde, as condições de sua prosperidade ou mesmo de sua sobrevivência- (BAUMAN, 2010).

Nessa sociedade, o envelhecer passou a ser objeto de preocupaçãopelo desconforto causado ao mundo capitalista predatório e veloz; que valida e valora o indivíduo na medida em que ele é capaz de consumir, produzir e assim movimentar o progresso da máquina do capitalismo parasitário.

Dessa forma, percebe-se claramente que a sociedade capitalista parasitária é uma sociedade que tem como lógica própria a de tudo desenraizar e a todos excluir, porque tudo deve ser lançado no mercado, tudo tem que ser sinônimo ou equivalente à riqueza que circula no mercado (MARTINS, 2009).

Essa forma social expõe limites nunca antes expostos com igual magnitude e intensidade, resultado de sua forma contraditória e, por isso, destruindo, de forma devastadora, direitos constituídos ao longo, especialmente, dos últimos cem anos (FRIGOTTO, 2010).

$\mathrm{Na}$ era do capital, aquele que não produz, aquele que não se insere é mal visto ou deixa de ser visto - e parte do preconceito e da indiferença para com os idosos surge desta premissa arraigada cada dia mais no seio da sociedade (CEDENHO, 2014).

Assim, nessas sociedades baseadas na lógica do consumo, representadas por relações líquidas e parasitárias,nada nem ninguém pode reivindicar isenção à regra universal do descarte, tampouco ter a permissão de se tornar indesejável (BAUMAN, 2007).

Como resultado dessa sociedade cada vez mais complexa, que exige uma nova postura diante da existência, especialmente de sua duração como condição essencial para a própria sobrevivência nesse sistema parasitário, "a velhice passou a se apresentar como fenômeno não somente biológico, mas fundamentalmente social" (RAMOS, 2014, p.23).

\section{Lixo Humano e a Necessidade De RessignificaÇão Do Valor Humano}

Apesar de a população idosa ser uma crescente mundial, não há, ou deixou há muito tempo de existir, um reconhecimento da pessoa idosa como aquela portadora de sabedoria, de conhecimentos, e, portanto, digna de seu valor humano (CEDENHO, 2014).

Segundo Bauman(2008), esse movimento de retirada de valor do conhecimento acumulado pelas 
pessoas envelhecidas ou nãoé um das características da sociedade líquido-moderna.

Devido à essa liquidez nas relações e à velocidade e necessidade de superconsumo, a velhice passou a ser uma fase da vida socialmente desvalorizada, negativamente representada, o que se reflete na qualidade de vida dos idosos (LARANJEIRA, 2010).

O capitalismo, por meio do controle das práticas temporais, espaciais e dos meios de produção, alocou e realocou o tempo de vida ou o tempo social, redefinido pelas necessidades reprodutivas ampliadas do capital o tempo de envelhecer, o qual passou a ser objeto de controle social, fonte de experiências negativas associadasà desvalorização (TEIXEIRA, 2006).

Em decorrência dessa construção é que "o idoso tem sua imagem associada à decadência, à perda de habilidades cognitivas e de controles físicos e emocionais, fundamentos importantes da autonomia dos sujeitos" (DA FONSECA; GONÇALVES, 2003, p. 2) estigma que resulta em outro panorama na perda da vontade de viver por parte dos idosos.

Prova disso é que, de acordo com o comunicado de imprensa do Comitê Federal de Controle e Avaliação sobre Eutanásia da Holanda, publicado em 3 de março de 2020, os números referentes aos documentos de registro examinados entre $1^{\circ}$ de janeiro de 2019 e 31 de dezembro de 2019, revelam que $67,8 \%$ dos pacientes tinham mais de 70 anos e 39,3\% tinham mais de 80 anos; já em pacientes com menos de 40 anos o percentual permaneceu limitado a 1,5\% (FEDERALE OVERHEIDSDIENST, 2020).

Em razão disso, o governo holandês abriu discussões para a implementação de uma lei até o fim de 2020, que se destina a idosos com mais de 70 anos, lei essa que prevêa disponibilização de uma pílula letalaos idosos que não desejam continuar vivendo e decidem encerrar sua existência. Contudo os debates, conforme site oficial do Governo do país, encontram-se suspensos por causa da pandemia do COVID-19 (MINISTERIE VAN VOLKSGEZONDHEID, 2020).

Tais acontecimentos apenas confirmam o fato de que asociedade está vivendo de forma binária, posto que existem duas humanidades numa mesma sociedade. Uma é constituída de integrados que estão incluídos no circuito reprodutivo das atividades econômicas, de produção e consumo e, a outra, se constitui numa sub-humanidade que se baseia em insuficiências e privações que se desdobram para além do fator econômico, excluídas, descartadas, párias (MARTINS, 2009).

As novas formas que assumem as relações sociais de produção e consumo do sistema capital são responsáveis pela situação de miséria absoluta de um terço da humanidade. Neste caso, há uma exclusão, também no sentido de extermínio, pela fome e endemias, cujas principais vítimas são crianças e velhos (FRIGOTTO, 2010).

Assim, aquele que não corresponde ao fluxo voraz dessa sociedade é tratado como lixo, o qual, segundo Bauman (2007), é o principal e comprovadamente mais abundante produto da sociedade líquida moderna de consumo, sendo a remoção do lixo e não ser jogado no lixo os dois maiores desafios da vida líquida, visto que num mundo repleto de consumidores e produtos, a vida flutua desconfortavelmente entre os prazeres do consumo e os horrores do desprezo da pilha de lixo.

Neste cenário, "a sociedade moderna é uma grande massa de população sobrante que tem pouco ou nenhuma chance de ser reincluída nos padrões atuais de desenvolvimento econômico" (MARTINS, 2009, p. 32). E quando analisada da perspectiva do envelhecido, Bosi é categórico ao afirmar que: "esta sociedade rejeita o velho, não oferecendo nenhuma sobrevivência a sua obra. Perdendo a força de trabalho ele já não é produtor nem reprodutor" (1994, p. 78).

Neste sentido, destaca-se o apontamento realizado por Véras e Felix (2016), os quais revelam que em 2010 quase $84 \%$ dos idosos brasileiros viviam nas cidadesnas áreas mais pobres e precárias. Fato que, segundo Fornasier e Leite "demonstra que, além de serem segregados do restante da população em razão do envelhecimento natural dos seus corpos e mentes, também o são em razão do declínio de sua condição econômica (perda da capacidade produtiva)" (2018, p. 2095).

A solução para tal problemática está longe de ser descarte de quem um dia já foi produtivo. Os seres humanos não são descartáveis, pelo contrário, são adaptáveis, resilientes e capazes de se reinventar.

O desprezo, a exclusão e o descarte atingem diversos grupos em toda sociedade, comprometendo de forma mais agressiva a existência prolongada. Dessa forma, "faz-se necessário concentrar forças e seguir adiante para promover uma cultura de paz e solidariedade, em especial aos que estão à margem" (ALMEIDA; ARONE; SANTANA, 2019, p. 47).

Nas palavras de Morin, em seu livro "A Cabeça Bem Feita", "devemos resistir ao nada. Devemos resistir às extraordinárias forças de regressão e de morte. Em todas as hipóteses devemos resistir. Frear a morte é resistir" (1999, p. 62).

Logo, para que o ser humano consiga concretizar o direito à vida plena e digna, deve socialmente permitir-se que essa vida maior seja igualmente melhor (LARANJEIRA, 2010).

A respeito desse assunto cabe o alerta de que:

A temática do desprezo nos introduz aos grandes desafios de nosso tempo: a questão da crise das populações, com fome, em situação de refúgio, em situação de rua, semterra, bem como a situação dos idosos, entre outras. 
E também nos leva a refletir sobre a emergência da discussão sobre as diferenças e as desigualdades sociais, remetendo à ideia de direitos, na luta por dignidade e democracia (ALMEIDA; ARONE; SANTANA, 2019, p. 41).

Levando em consideração um conceito mais transdisciplinar do ser idoso, Sá (2002) aponta que o idoso é um ser de seu espaço e de seu tempo, sendo o resultado do seu processo particular de desenvolvimento e do seu curso de vida, em queele revela a expressão das suas relações e interdependências, fazendo parte de uma consciência coletiva, a qual o introjeta em seu pensar e em seu agir, descobrindo suas próprias forças e possibilidades, estabelecendo conexão com as forças dos demais, criando, assim, forças de organização e de transformação social e política.

Assim, seja qual for a ótica em que se discuta ou escreva acerca da velhice, é desejável respeitar os direitos intangíveis ou intocáveis do cidadão idoso (FERNANDES, 1997). Portanto, imperioso para isso, é uma reformulação fundamental e profunda nas responsabilidades humanas dessa sociedade líquida, dos próprios idosos e do Estado como garantidor de direitos e bem-estar social.

Contudo, essa temática demanda discussão mais ampla, ficando aberta a possibilidade de desenvolvimento do tema, sendo certo que, de toda forma, a ressignificação do valor humano, a proteção e defesa da dignidade da pessoa humana e dos direitos da personalidade devem ser prioridade para se combaterem as diretrizes estabelecidas pelo capitalismo parasitário, que descarta de forma sumária os idosos que não se enquadram nos seus modos de produção e consumo.

\section{Considerações Finais}

O processo de envelhecimento ocorre de forma não linear, sendo um processo particular e individual de cada ser humano, que em sua humanidade é influenciado pelos diversos setores sensíveis da vida em que está inserido.

Contudo, na sociedade moderna do consumo, na qual o capital é quem valora a vida humana, parece existir um ponto central, uma regra estruturante, a de quetodos serão em algum momento da vida excluídos de alguma forma (BAUMAN, 2008).

A exclusão social moderna retira da pessoa humana os seus valores básicos, o que conduz à anulação da identidade humana, com a violação sistemática da dignidade humana na forma apresentada por Kant, uma vez que reduz o ser humano a um corpo produtivo ou improdutivo, ou a algo que não tem valor, retirando sua autonomia e tolhendo a amplitude de suas relações sociais.

Para os idosos, essa regra vem se aplicando de forma quase que sumária devidoà construção pejorativa de que com o avançar da idade se perde acapacidade de produzir, consumir e movimentar a riqueza dessa sociedade parasitária.

Notável se torna a percepção de que o valor humano dessa parcela da população tem sido retirado e invalidado. Estas pessoas sofrem quase que diariamente com as diversas formas de violações à sua dignidade. Para Simone de Beauvoir "essa sociedade não é apenas culpada, mas também é criminosa, pois abrigada por trás do mito da expansão e da abundância, trata os velhos como párias" (1990, p. 8).

Os envelhecidos estão marginalizados e estão junto de um grande grupo de excluídos e descartáveis, no qual se encontram também os deficientes, as mulheres, os desempregados, os refugiados e tantos outros, os quais passaram a serem considerados problemas sociais, lixos humanos.

A partir dessa percepção, Morin (1999) propõe que, se faz imperiosa uma mudança estrutural na qualse tome a consciência de que é necessário mudar o paradigma do desenvolvimento econômico para um paradigma de desenvolvimento a favor do ser humano, para, assim, a sociedade alcançar um grau mínimo de humanidade, em que sua meta principal seja o desenvolvimento das potencialidades psíquicas, espirituais, éticas, culturais e sociais.

Surge, então, a necessidade urgente de uma grande reforma, que começa primeiro no pensamento dos idosos, para que estes notem que é possível o envelhecimento com muitas possibilidades e capacidades diferentes daquelas que foram programadas e estigmatizadas.

Segundo Santos (2010), para que isto possa ocorrer,torna-se necessário se ter como princípio estruturante dessa nova forma de sociedade o viver melhor, o viver verdadeiramente, o que significaria viver com compreensão, solidariedade e compaixão.

Portanto,"cabe à sociedade assumir a defesa dos direitos dos idosos, com base numa solidariedade intergeracional consciente e sem reservas, deixando, assim, a terceira idade de ser objeto de olhares pejorativos e passando a ser respeitada" (MARGARIDA et al., 2012, p. 7).

Por último e não menos importante, necessária é a retomada do papel do Estado, que atualmente figura como preposto submisso das vontades do capital, passando a reintegrar-se àsua função de garantidor dos direitos múltiplos e necessidades humanas.

É certo que tal discussão é complexa e envolve os âmbitos de possíveis desenvolvimentos legislativos, de política pública no campo da assistência e previdência social e, ainda, de promoção da conscientização a respeito do valor humano da pessoa idosa e da interdependência de suas relações sociais com o desenvolvimento da sociedade numa 
perspectiva que ultrapasse 0 enfoque puramente econômico, posto que, de nada adianta alcançar índices econômicos elevados, se tal corpo social nem mesmo é capaz de prover a dignidade da camada populacional que mais cresce e para a qual todos tendem a caminhar.

Entretanto, "não se trata também de negar a extrema importância da esfera econômica. A crítica se dirige à percepção unilateral da economia como única esfera da vida que merece atenção" (SOUZA; GRILLO, 2009, p. 8).

Logo, temos que, apesar da importância da economia para o bem-viver, um dos critérios pelo qual se terá de avaliar o grau de "humanidade" da sociedade é o do lugar e o papel que se reserva aos idosos na vida social, um lugar onde, quer na sociedade, quer no quotidiano, as pessoas estejam organizadas de tal modo que os idosos tenham lugar, valor e papel na vida social (LARANJEIRA, 2010).

Assim, as principais contribuições deste trabalho são a imprescindível ampliação da reflexão sobre como a pessoa idosa é afetada pela cultura de descarte imposta numa sociedade parasitária, a tentativa de dar visibilidade à realidade social enfrentada poresta parcela da população em grande ascensão, a discussão proposta a respeito do esvaziamento da autonomia e dos valores inatos a humanidade que se impõem aos envelhecidos e, por fim, a concepção de críticas construtivas e sugestões para se pensar como mudar o lugar que essa população vem ocupando.

Contudo, devido ao fato de esse estudo ser eminentemente teórico e construído por meio de lógica dedutiva,as principais limitaçõesdesta pesquisa são a análise social adstritaà construção de argumento e discussões sem aconfirmação específica em dados numéricos; bem como restrição às análises referencias.

\section{Referências Bibliográficas}

1. ALMEIDA, C. R. S. DE; ARONE, M.; SANTANA, A. J. DE. Humanizar o humano: entre o desprezo e a dignidade. Revista Flecha do Tempo, n. 1, p. 33-50, 2019.

2. ARENDT, H. A Condição Humana. $10^{\mathrm{a}}$ ed. Rio de Janeiro: Forense Universitária, 2008.

3. ASRI, V. Targeting of social transfers: Are India's poor older people left behind? World Development, v. 115, p. 46-63, 2019.

4. BAUMAN, Z. Vida Líquida. Rio de Janeiro: Jorge Zahar, 2007.

5. BAUMAN, Z. Vida para o Consumo. Rio de Janeiro: Jorge Zahar, 2008.

6. BAUMAN, Z. Capitalismo Parasitário e outros temas contemporâneos. Rio de Janeiro: Jorge Zahar, 2010.

7. BEAUVOIR, S. DE. A Velhice. 1. ed. Rio de Janeiro: Nova Fronteira, 1990.
8. BOFF, L. O cuidado essencial: princípio de um novo ethos. Inclusão Social, v. 1, n. 1, p. 28-35, 2005.

9. BOSI, E. Memória e Sociedade. 7. ed. São Paulo: Companhia Das Letras, 1994.

10. BOURDIEU, P.; WACQUANT, L. A nova bíblia do Tio Sam. Le monde diplomatique, v. 1, n. 4, mar. 2001.

11. BRAGA, R. P.; LEITE, F. P. A.; BAHIA, C. J. A. GARANTIAS FUNDAMENTAIS DA ÃO POR DIREITOS PESSOA IDOSA: UMA REVOLUÇÃO Rumo À INCLUSÃO. Academia Brasileira de Direito Constitucional, v. 9, p. 431-450, 2017.

12. CEDENHO, A. C. O Idoso como Novo Personagem da Atual Sociedade: O Estatuto do Idoso e as Diretrizes para o Envelhecimento no Brasil. Revista do Curso de Direito da Faculdade de Humanidades e Direito, v. 11, n. 11, p. 9-46, 2014.

13. CRESPO, A. P. A.; GUROVITZ, E. A pobreza como um fenômeno multidimensional. RAE eletrônica, v. 1 , n. 2, p. 1-12, 2002.

14. DA FONSECA, M. M.; GONÇALVES, H. S. Violência contra o idoso: suportes legais para a intervenção. Interação em Psicologia, v. 7, n. 2, p. 121-128, 2003.

15. FEDERALE OVERHEIDSDIENST. Persbericht van de Federale Controle- en Evaluatiecommissie Euthanasie - FCEE. VOLKSGEZONDHEID, VEILIGHEID VAN DE VOEDSELKETEN EN LEEFMILIEU, 2020. Disponível em: <https://leif.be/ data/press-articles/fcee_cijfers-2018_persbericht_ 3. pdf > . Acesso em: 6 abr. 2020

16. FERNANDES, A. T. Desigualdades e representações sociais. Revista da Faculdade de Letras: Sociologia, v. 10, p. 203-214, 2000.

17. FERNANDES, F. DA S. As pessoas idosas na legislação brasileira: direito e gerontologia. 1. ed. São Paulo: Editora LTr, 1997.

18. FORNASIER, M. DE O.; LEITE, F. P. A. The Social Exclusion of the Elderly in the Urban Environment. Revista de Direito da Cidade, v. 10, n. 3, p. 2073-2105, 2018.

19. FRIGOTTO, G. Exclusão e/ou Desigualdade Social? Questões teóricas e político- práticas. Cadernos de Educação (UFPEL), n. 37, p. 417-442, 2010.

20. HADDAD, E. G. DE M. A ldeologia da Velhice. 1. ed. São Paulo: Editora Cortez, 2017.

21. HEBLING, E.; RODRIGUES, C. K. O Estatuto do idoso e a saúde bucal. Robrac, v. 15, n. 39, p. 51-56, 2006.

22. KANT, I. Fundamentação da Metafísica dos Costumes. Traducao Pedro Quintela. Lisboa: Edições 70, 2011.

23. LARANJEIRA, C. A. "Velhos são os trapos": Do positivismo clássico à nova era. Saude e Sociedade, v. 19, n. 4, p. 763-770, 2010.

24. LEVITAS, R. et al. The Multi-Dimensional Analysis of Social Exclusion. Bristol: University of Bristol, 2007. 
Disponível em: <https://repository.uel.ac.uk/ download/469129f180d3060ed6707d32474ae3d29 ac0b9635ca19758f989a09936a3a319/1819926/mult idimensional.pdf >. Acesso em: 6 abr. 2020.

25. LUHMANN, N. Globalization or World society: How to conceive of modern society? International Review of Sociology, v. 7, n. 1, p. 67-79, 1997.

26. MACLEOD, C. A. et al. Re-thinking social exclusion in later life: a case for a new framework for measurement. Cambridge University Press, v. 39, n. 1, p. 74-111, 2017.

27. MARGARIDA, S. et al. A Depressão no Idoso. Millenium, v. 43, p. 79-94, 2012.

28. MARTINS, J. DE S. Exclusão Social e e a Nova Desigualdade. 4. ed. São Paulo: Paulus, 2009.

29. MAZZEO, A. C. Burguesia e Capitalismo no Brasil. São Paulo: Ática S.A, 1995.

30. MINISTERIE VAN VOLKSGEZONDHEID, W. EN S. Maatschappelijke dialoog laatste levensfase van start. Disponível em: <https://www.rijksoverheid.nl/ actueel/nieuws/2020/01/16/maatschappelijkedialoog-laatste-levensfase-van-start>. Acesso em: 6 abr. 2020.

31. MORIN, E. La Tête Bien Faite - Repenser la réforme, réformer la pensée. $8^{a}$ ed. Paris: Éditions du Seuil, 1999.

32. PAN AMERICAN HEALTH ORGANIZATION (PAHO). Plano de Ação sobre a Saúde das Pessoas Idosas, incluindo envelhecimento ativo e saudável para o período 2009-2018. Washington, D.C. Disponível em: <https://www.paho.org/hq/index.php?option= com_docman\&view $=$ download\&alias $=48594$-ce 164-inf-6-p-pda-idosos-relatorio-final\&category slug $=164$-comite-executivo\&ltemid $=270 \&$ lang $=$ pt>. Acesso em: 6 abr. 2020.

33. PAULA, M. F. DE. Os idosos do nosso tempo e a impossibilidade da sabedoria no capitalismo atual. Serviço Social \& Sociedade, n. 126, p. 262-280, 2016.

34. RAMOS, P. R. B. Curso de direito do idoso. São Paulo: Saraiva, 2014.

35. SÁ, J. M. DE. A formação de Recursos Humanos em Gerontologia: Fundamentos epistemológicos e conceituais. In: Tratato de Geriatria. Rio de Janeiro: Guanabara Koogan, 2002. p. 1119-1124.

36. SANTOS, S. S. C. Concepções Teórico-filosóficas Sobre Envelhecimento, Velhice, Idoso e Enfermagem Gerontogeriátrica. Revista Brasileira de Enfermagem, v. 63, n. 6, p. 1035-1039, 2010.

37. SARMENTO, D. Dignidade da Pessoa Humana: conteúdo, trajetórias e metodologia. $2^{\mathrm{a}}$ ed. Belo Horizonte: Forúm, 2016.

38. SEN, A. Desenvolvimento como Liberdade. 8. ed. São Paulo: Companhia de Bolso, 1999.

39. SILVA, E. L.; SILVA, J. A. Envelhecer nas perspectivas sobre tempo, experiência e consciência de classe em Edward Palmer Thompson e Antônio Gramsci. Revista Brasileira de Ciências do Envelhecimento Humano, v. 14, n. 2, p. 118-128, 2018.

40. SIQUEIRA-BATISTA, R.; SCHRAMM, F. R. A saúde entre a iniqüidade e a justiça: contribuições da igualdade complexa de Amartya Sen. Ciência \& Saúde Coletiva, v. 10, n. 1, p. 129-142, 2005.

41. SOUZA, J. A ralé brasileira: quem é e como vive. Belo Horizonte: Editora UFMG, 2009.

42. TEDESCO, J. C. Os fenômenos de segregação e exclusão social na sociedade do conhecimento. Cadernos de Pesquisa, n. 117, p. 13-28, 2002.

43. TEIXEIRA, S. M. ENVELHECIMENTO DO TRABALHADOR NO TEMPO DO CAPITAL: problemática social e as tendências das formas de proteção social na sociedade brasileira contemporânea. Tese de Doutorado. Universidade Federal do Maranhão, 2006.

44. TEIXEIRA, S. M. Aging and Reforms in the Social Security System in Contemporary Brazil. Textos \& Contextos, v. 17, n. 1, p. 126, 2018.

45. UNFPA. Ageing in the Twenty-First Century: A Celebration and a Challenge. Nova York: UNFPA and HelpAge International, 2012. Disponível em: $<$ https://www.unfpa.org/publications/ageing-twentyfirst-century >. Acesso em: 6 abr. 2020.

46. VÉRAS, M. P. B.; FELIX, J. Questão urbana e envelhecimento populacional: breves conexões entre o direito à cidade e o idoso no mercado de trabalho. Cadernos Metrópole, v. 18, n. 36, p. 441-459, 2016. 